\title{
O DISCURSO INTERROMPIDO E A PERVERSA DESTRUIÇÃO DOS CORPOS: UMA BREVE ANÁLISE DE DOIS CONTOS DE LÍDIA JORGE
}

\author{
THE INTERRUPTED SPEECH AND THE \\ PERVERT DESTRUCTION OF THE BODIES: A \\ BRIEF ANALYSIS OF TWO SHORT \\ STORIES OF LIDIA JORGE
}

Viviane Vasconcelos ${ }^{1}$

\section{RESUMO}

Este artigo objetiva analisar dois contos da escritora Lídia Jorge, "Marido" e "As três mulheres sagradas", publicados em momentos diferentes da obra da autora, mas que parecem ter alguns caminhos convergentes de leitura, como o silêncio, ao qual estão submetidas algumas personagens, e a violência, que resulta da transgressão das regras. Em ambos os textos, as temáticas encontram força na elaboração da linguagem de cada conto.

PALAVRAS-CHAVE: Lídia Jorge; escrita; silêncio.

\section{ABSTRACT}

This article aims to analyze two short stories by the writer Lídia Jorge, "Marido" and "As três mulheres sagradas", published at different moments of the author's work, but which seem to have some convergent paths of reading, such as silence, to which they are subjected some characters, and the violence, that results from the transgression of rules. In both texts, the themes find strength in the elaboration of the language of each story.

KEYWORDS: Lídia Jorge; writing; silence. 
Em entrevista ${ }^{2}$ concedida à Revista Desassossego, em julho de 2012, a escritora portuguesa Lídia Jorge fala sobre a necessidade de inserir a literatura em permanente diálogo com questões sociais, políticas e históricas e, como consequência da discussão, da importância da relação entre mulheres e palavras na sua obra. Questionada sobre o que compreende ser o poder da palavra nas personagens que são mulheres, a escritora estabelece uma diferença em comparação a outra escrita, a de Agustina Bessa-Luís, no que diz respeito à composição das personagens, e cita uma das conversas que tiveram. Lídia Jorge analisa que as mulheres das obras agustinianas são dotadas de conhecimento, "conseguem dominar os outros no ter, no haver, no domínio da família, no domínio do amor” (JORGE, 2012, p.204), mas as suas, ao contrário, aparecem como "figuras do olhar, aquelas que observam, e que observam o poder, também, e observam o poder das outras (...)", "aquela que nasce para dizer "eu não tenho as palavras" (JORGE, 2012, p. 205).

A conclusão à qual chega a escritora, que as personagens da sua obra problematizam a linguagem e que serão, por conseguinte, mais próximas do que denominaria como figuras do olhar, parece ser uma sugestão interessante para a leitura de dois contos de seus contos: "Marido", publicado em Marido e outros contos (1997), e "As três mulheres Sagradas", texto inserido na coletânea $O$ belo adormecido (2004). Os livros citados reúnem alguns contos da escritora que já haviam sido publicados em jornais e em revistas. Como alerta Marlise Vaz Bridi, em introdução a uma outra antologia da autora, editada pela Leya em 2014, não há um eixo ordenador em "Marido e outros contos", mas cada história convoca o leitor "a participar da elaboração rigorosa do sentido verdadeiro ou abominável da vida, passo a passo" (BRIDI, 2014, p.11), constatação que pode também servir à análise de "As três mulheres sagradas".

O conto "Marido" termina com a violenta cena da morte de Lúcia, personagem central da narrativa, momento em que a luz da vela, simbolicamente lida como sinônimo de clareza e de vida durante o conto, é ressignificada pelas mãos do marido da porteira, pois "se sente atraído pelo brilho da vela, direita, ateada” (JORGE, 2014, p.25). É por meio da descrição das últimas cenas, detalhadamente relatadas, que há uma ruptura de expectativa do leitor. No lugar de gritos e de gestos de desespero, há uma elaboração demorada, fragmentada, minuciosa e, sobretudo, silenciosa da linguagem, como podemos perceber:

Ele toma a vela, traz a vela, traz a vela do Rex e da Regina até junto da porteira, puxa-lhe a roupa, aproxima a vela da camisa de nylon, com brilho e em silêncio. Ateia. Ateou? Ateou a camisa? Ela vira-se, sai da cama, esfrega-se na parede, o fogo primeiro não alastra, depois alastra, cola, passa ao cabelo, ela remove-se no chão, na carpete da sala, junto da porta, ainda abre a porta, mater vita, ó doçura, ventris tui nobis post hoc exilium, ostende! Ó clemens, ó pia, advocata, em silêncio, dulcis Virgo Maria! A porta está aberta para toda a 
chama. A chama da porteira sai pela escada de serviço abaixo, correndo sem ruído até ao oitavo, ao sétimo, ao sexto. Só no quinto a chama de porteira para. Crepita. É a porta do advogado do quinto. Sem barulho, fica à porta do advogado, das testemunhas e da lei. (JORGE, 2014, p. 25-26)

Antes da análise do fragmento, citamos dois trechos de "As três mulheres sagradas", narrativa que começa já no avançar da história, no momento em que um grupo de jovens encontra uma mulher chamada Vera Brandão, de cuja personalidade o leitor toma conhecimento páginas depois, amarrada nua em um poste:

Quando acordou, tudo o que viu foram as suas roupas espalhadas pela areia e o seu próprio corpo amarrado ao poste. Claro que o poste ela não o via, porque a sua cabeça estava sujeita a ele, os braços atados atrás das costas, e entre os seus seios, ao fundo deles, como se fossem de outra pessoa, estavam os seus próprios pés. Mas as quatro peças de vestuário que começavam a alvejar à luz da madrugada é que lhe devolveram a memória dos vultos e das mãos que lhe haviam feito aquilo. (JORGE, 2014, p. 133)

Então procurou escutar numa e outra direção, para ver se lhe chegava algum sinal das suas pessoas, mas apenas ouviu o ruído do mar, o barulho das ondas caindo em cima da areia como toalhas de água. Nesses momentos, uma pessoa fica muito pouco lúcida, ou fica lúcida de outra maneira, como se os olhos mudassem de lugar. A prova é que foram essas porções de água que vinham espalhar-se em semicírculos a escassos metros da estrada, foram elas que lhe deram a ideia de que tudo aquilo poderia ter um sentido, e por isso permaneceu quieta a olhar para o seu próprio corpo, a ver a partir de cima, por entre o côncavo dos seios, as curvas redondas dos joelhos, e as pontas dos pés inchados. (JORGE, 2014, p. 133-134)

Os dois textos de Lídia Jorge, publicados em períodos diferentes de sua obra e aparentemente com temáticas distintas, parecem revelar algumas posições acerca da possibilidade de dizer para duas mulheres, Lúcia e Vera Brandão, bem como o tratamento dado a essa questão, pois o fato de serem vítimas da violência do discurso interrompido ou da incapacidade de falar resulta, em ambos os casos, na perversa destruição dos corpos. Começar pelas ações mais impactantes dos dois textos não traz prejuízo à leitura porque, mesmo estando o primeiro fragmento nas últimas páginas do conto e a segunda cena nas linhas iniciais do texto, produzirão um silêncio do qual o leitor não poderá escapar. As ações abrem uma zona de desconforto que estará presente nas duas narrativas, quer pela presença das mulheres "sem voz", quer pela elaboração da linguagem. Os dois textos não oferecem, a rigor, nenhum outro prejuízo além do estado de perda causado pela violência, resultado último, nos dois textos, da incapacidade de dizer além dos corpos. Se, como afirma Simone de Beauvoir (1980), “(...) o corpo 
da mulher é um dos elementos essenciais da situação que ela ocupa neste mundo", nas duas narrativas são muitos os indícios que levarão à tentativa de anulação da matéria, pois as duas personagens despertam diferentes insatisfações nos espaços que transitam, como também nos seus interlocutores. Em outras palavras, os corpos das duas mulheres são irrelevantes porque, como veremos, nem ao aspecto fisiológico elas atendem.

Em "Marido", o que inicialmente desperta a atenção é a construção frasal repetitiva, a preocupação com uma linguagem que signifique sufoco e opressão, um sintoma da sociedade retratada no texto, que remonta à época do Salazarismo, e que será traduzida, por exemplo, pelo excessivo uso de pontos finais. Às frases elípticas, fragmentárias e entrecortadas, soma-se a inserção constante de orações, que são súplicas de Lúcia ou um diálogo com suas únicas interlocutoras, mas que também contam a história cotidiana do seu casamento:

Marido: Salve, Regina, mater misericordiae, vita, dulcedo spes, imensa doçura, salva e vem. Vem, e abafa a vida, a roupa, a sala e o fogão, abafa a espera com o teu doce bafo. Ampara a vela, acende o fósforo, concentra o ar, protege da aragem e chama da vela até ele vir. Abafa o sim, protege o som da ira dos inquilinos até ele tocar. Esconde-te invisível, acocora-te, vita, advocata, mãe suprema (...). (JORGE, 2014, p. 17)

O texto começa com uma oração, uma referência apelativa à Salve Regina e, depois, à Ave Maria, pois o marido, descrito apenas no seu papel matrimonial e sem o artigo definido no título do conto, trabalha na oficina até às cinco, embora os outros colegas trabalhem até mais tarde. Religiosamente, de cinco às sete, o marido "prefere passar em sítios que a porteira nem nomeia" e sai de lá "com os olhos cheios do brilho do vidro" (JORGE, 2014, p. 18). A cena se repete diariamente: a porteira acende uma vela, pede que o marido chegue para jantar e que não faça barulho a fim de não incomodar os vizinhos. Esses, em geral, são profissionais liberais, como o advogado do quinto andar, e frequentemente reclamam do marido, pois sempre retorna embriagado do trabalho a chamar por Lúcia, a porteira, ainda na escada.

É interessante notar que no campo semântico haja a reprodução de uma atmosfera sonora frequentemente interrompida, como "abafar", sem "ruído" e "silêncio", vocábulo inadequado, por exemplo, para a dor da vela que queima no corpo da porteira no momento da sua morte. Essa atmosfera silenciosa ocorre desde o início da narrativa quando, por exemplo, Lúcia se esconde atrás do pombal clandestino da varanda ou quando ela pede pela salvação do seu casamento, do mundo e de seu marido:

No alto do grande mundo da madrugada. Salvem-na deste mundo, levem-na no escuro, tratem-na com doçura enquanto se esconde. Master misercordiae, abre as asas, abafa o som do coração da porteira, apaga a vista do marido dela a luz que posso iluminar o ângulo escuro onde a porteira está escondida. (JORGE, 2014, p. 19) 
É com voz muito doce que a porteira ao cair da noite se põe a chamar à janela pela Regina, cantando como o padre Romão canta para atingir o coração do rex através da Regina. Pela salvação do mundo. Mas não canta alto como o padre Romão canta, movendo com as mãos a voz do coro. Pelo contrário, ela canta baixo, às vezes só move os lábios à janela para não atrair a ira dos inquilinos. (JORGE, 2014, p. 19-20)

Além do jogo entre o claro e o escuro, atmosfera na qual Lúcia pretende sempre ficar, escondida, com o coração "abafado" para não sofrer, nota-se também que o medo a paralisa, o que contribui ainda mais para o silêncio: ela canta baixo, não move o corpo, não quer ser notada e não quer se tornar visível, apesar de ter de interagir com os demais moradores do prédio em função do cargo que exerce, anulado pela ausência de interação com o público em detrimento da sua vida particular, que também não existe. A angústia da espera e a voz baixa, que só é ouvida nas orações, por exemplo, não poderiam produzir a doçura da porteira, que é "doce" até na hora da morte, conformada com a vida e seu destino, e que só exercera, ainda que dolorosamente, um único papel social, o de esposa. Quando essa função é ameaçada pelo advogado, que sugere a ela uma separação, a mulher se desespera:

Aí a porteira entendeu que se haviam congregado todos contra o seu homem e perdeu a doçura, nesse dia mesmo. E perdeu a doçura porque um homem é um homem, spes nostra, ad te clamamos, Rex Jessus, benedictus fructus ventris tui nobis post hoc exilium, ostende. E assim sucessivamente. Isto é, um homem é um homem e um sacramento ainda é mais do que um homem porque esse é uma liga entre dois e nem parte dele parece na Terra. Oh, vita, dulcedo! (JORGE, 2014, p. 21)

Fica claramente estabelecido na leitura do trecho acima o medo que Lúcia tem de perder a sua identidade, que é desenvolvida por meio da vida do marido. O advogado, que, assim como o médico, é conhecido pela profissão e sua atuação na esfera pública, não compreendia que a função de esposa que Lúcia desempenhava, ainda que regida pelo signo da vigília constante e do pavor do desaparecimento do marido, não era só legitimada pela assinatura do papel, mas fazia parte da ordem da existência da personagem.

A consciência de que a mulher, conforme a narrativa, faz parte de um corpo social caracterizado pela biologia e por uma condição que lhe impõe a reserva, a contenção e a acomodação, é expressa na figura da protagonista, de quem não sabemos detalhes físicos, mas apenas características comportamentais, dando a compreender que Lúcia é um exemplo de mais um corpo que está "no centro de toda relação de poder", conforme analisa a historiadora Michelle Perrot (2005, p. 447) quando fala da importância da distinção entre as construções simbólicas dos corpos masculino e feminino na história ocidental. Por essa razão, convocando o pensamento de Perrot, a porteira se põe sempre numa posição subordinada, embora o 
marido esteja sempre alcoolizado e, portanto, também em uma situação fragilizada.

A manutenção do espaço patriarcal é soberana diante da vida de Lúcia que, ao responder pela primeira vez ao comportamento do marido, esperando-o sem se esconder, acaba por se destruir nas chamas da vela que fora sempre a intermediária entre o mundo real e uma outra realidade, iluminada e superior. É a mesma vela, objeto que une matéria e espírito no cristianismo, que surge como ponte que a levará ao silêncio final. É a primeira vez que a porteira não se esconde e se ilumina.

Em toda a cena que citamos no início deste artigo, a culpa é retirada, mais uma vez, do homem, o marido, e todo o cenário se centra lentamente na ação do fogo sobre o corpo da porteira, em uma narrativa em forma de oração que acaba silenciosamente em um pedido do narrador para que a morte não desperte a atenção de nenhum morador do prédio: "Levem-na, Regina e Rex, com vossas quatro mãos, vossos quatro pés, deste lacrimarum valle, eia ergo, ad nos converte. Levem-na sem ruído, sem sirene, sem apito, sem camisa, sem cabelo, sem pele, post hoc exilium, ostende". (JORGE, 2014, p. 26).

Além disso, retomando os instantes finais da narrativa, é importante notar que, apesar de não reagirem, marido e porteira, cada passo da destruição de Lúcia ocorre numa descrição excessiva: a chama do cabelo, a descida pelos andares do prédio, por exemplo. O excesso da ausência se dá por meio da observação do narrador, testemunha de todo o horror das linhas finais e que pede para que Lúcia seja levada, ainda que não reste mais nenhum vestígio da mulher. Vale lembrar, ainda, que o leitor só tem conhecimento do nome pelos gritos permanentes do marido quando chegava do trabalho, pois a ele era dado o direito de gritar: “- Lúcia! Ó Lúcia! E o chamamento atravessa as paredes do pequeno décimo, contíguo às chaminés e às antenas (...)" (JORGE, 2014, p. 19). A ela, nem no momento da morte, foi concedido o grito na hora em que o corpo estava posto em chamas. Se aprendemos com Blanchot (2005) que a palavra é também o vazio, o que nos remete a uma reflexão importante sobre a ausência da linguagem, que é nulidade, falta, perda, isto é, está também na esfera do que às vezes não é possível ser dito, "Marido" é um exemplo de como a realidade pode gerar a irrealidade pelo esvaziamento total das palavras: "Sem barulho, fica à porta do advogado, das testemunhas e da lei” (JORGE, 2014, p. 26). Não há palavras da Lei, não há o que dizer, não há mais reza: as palavras são silenciadas pela violência.

Ainda que aconteça em outro ambiente, em "As três mulheres sagradas" também podemos refletir acerca de algumas questões que ocorrem no conto "Marido". Narrativa incluída em O belo adormecido, trata-se de mais um conto da coletânea que tem como paisagem o mar/praia do Sul de Portugal, imagem que pode nos remeter a uma fuga ou a uma calmaria, bem diferente do espaço opressivo do prédio da porteira. Na primeira 
página do conto, Vera Brandão, amarrada ao poste, ouve o ruído do mar, o barulho das ondas. Ainda que estivesse em uma situação completamente frágil, conseguia ter a percepção sensorial do espaço à sua volta. Quando o grupo de jovens a liberta, o narrador observa:

Lembrava-se de ter permanecido muito quieta, à escuta, enquanto os passos e as vozes haviam cessado, provavelmente por efeito do estado de choque que o espectáculo das três sequestradas lhes estava causando, sobretudo a sua própria figura, perto da qual se encontravam. Compreendia. Quem quer que fosse que chegasse, encontrava-se sem capacidade de reagir. (JORGE, 2014, p. 136)

Decide, então, não dizer aos jovens a razão de estar naquela condição desumana e os fatos permanecem inconclusivos no decorrer da narrativa: “(...) não paravam de se debruçar sobre ela, tratando-a como pessoa" (JORGE, 2014, p. 137). É interessante a primeira observação acerca do cuidado que havia sido dado: a mulher, com o corpo violado, era um ser. Outro fato curioso é a violência não ter gerado a morte, mas a tentativa de uma humilhação pública que a faria desistir de algo que os leitores ainda não sabem: "O que tinha acontecido tinha acontecido, havia desaparecido no ar. Há passos nesta vida que devem ser preservados das acareações públicas para que se poupem os sentidos privados" (JORGE, 2014, p. 139).

Nos dois contos, o sentido do privado é superior ao do público. A mulher pode ser violentada, ter seu corpo corrompido, mas o último "desejo", nos dois contos, é o silêncio. Embora o narrador de "Marido" relate detalhadamente o que aconteceu no corpo de Lúcia, se cala diante dos motivos que resultaram na morte, assim como em "As três mulheres sagradas". O narrador se recusa a testemunhar o horror e também silencia. Como Lúcia, Vera Brandão não fala. Ouve, passivamente, os comentários dos jovens e toma conhecimento de que o corpo, que já não sentia por estar demasiadamente dolorido, devia impressionar o grupo, que rapidamente recolhia as roupas espalhadas na areia e procurava reverter a situação da mulher que estava "mais gelada que um peixe" (JORGE, 2014, p. 136).

Depois da violência inicial ocorrida em um matagal, o leitor descobre, aos poucos, quem são as duas companheiras às quais Vera Brandão se refere: Dinah de Sousa, mulher que sempre recorria às explicações da ciência para comprovar seus argumentos, e Julinha Moreira, católica praticante. Vera era líder de um projeto solidário que evitava o aborto, o Flores recolhidas, nome inspirado na expressão miúdas flores, da Quarta Elegia do poeta Rainer Maria Rilke: “Toda a energia concentrada na preservação da vida desde o seu início. A conviç̧ão construída como um ato racional. Tão simples, tão claro, uma flor na jarra" (JORGE, 2014, p. 141). A primeira provocação que surge, após o pavor da imagem da mulher amarrada ao poste, é o fato de sabermos que Vera Brandão é líder de um projeto solidário contra o aborto, pois quem tenta preservar a vida da mulher que opta por ter um bebê tinha sido brutalmente violentada. 
Criada para salvar pessoas, a instituição, no intervalo de um ano, havia conseguido mais de três mil assinaturas e, no período de três anos, acolhido mais de trinta e nove mulheres grávidas e em situação de risco. A chegada de Margarida Maria, jovem de 15 anos, abandonada pelo pai e pela mãe e que havia sido violada na noite de Natal, comoveu a líder da casa da Rua das Trinas. Vera Brandão decide usar Margarida para um plano de arrecadação de verbas para a associação e, com elas, rumo às praias do sul de Portugal, iriam Dinah e Julinha. O programa "Salvação da Vida" utilizaria Margarida como modelo: "Chamo-me Margarida. Salve com o seu apoio muitas outras margaridas (...). Deposite o seu donativo no Banco Barklays..." (JORGE, 2014, p. 149).

A menina grávida, que se parecia com a modelo Kate Moss, segundo o narrador, despertava a atenção dos rapazes, especialmente de um jovem surfista que o grupo encontrou em uma das abordagens e que passou a segui-las. Margarida não dizia nada: "Tinha os olhos baixos, a boca pequena muito fechada, nem se movia. Toda ela era impenetrável (...)" (JORGE, 2014, p. 153-154). Toda a narrativa é interceptada pelo silêncio devastador de Margarida, que aparece misteriosamente na associação e resolve participar do projeto de arrecadação com as colegas de Vera Brandão, mas que não fala.

Quando decidem finalizar a missão nas praias do Sul, param no hall de um dos hotéis e percebem que a perseguição de alguns homens, como a do rapaz da prancha, não era uma coincidência, como também aquele conjunto de fatos aparentemente desligados despertava cada vez mais a dúvida de estar ou não Margarida envolvida naquela situação, mas a jovem não respondia e "a realidade era duma complexidade ilegível" (JORGE, 2014, p. 165). A ilegibilidade dos fatos ou a explicação interrompida, que acontece por meio de ações que não são descritas completamente, incomodam o leitor, assim como no conto "Marido", numa revelação constante de que os sentidos, se existirem, não serão apreendidos pelo que está sendo dito, mas pela observação minuciosa das ações. Depois de levantar a hipótese de que o rapaz era o próprio violador de Margarida, de quem a jovem provavelmente gostava, a líder do grupo se revolta com o fato de o casal estar sendo protegido por outros homens. A valentia de Vera Brandão, ao gritar para as companheiras que elas são "pessoas de liberdade", parece incomodar os rapazes, assim como todos os objetos descritos pelo narrador e que darão a ela um aparente poder, como o carro da líder: "Era um BMW, tinha dois anos apenas, e fora das revisões, zero em oficina. Valente, potente" (JORGE, 2014, p. 167).

Ainda que desafiando o poder patriarcal, não só pela criação da instituição que dava abrigo a mulheres abandonadas pela sociedade, como também pela coragem em expor as ideias de seu projeto em regiões mais afastadas, perturbando as férias de muitas famílias, a líder não conseguiria vencer os comparsas do homem "da prancha". Na cena em que seu carro é fechado, mais uma vez o narrador se refere à Dinah e à Julinha com uma 
expressão de medo, pois estão mudas e arrependidas da missão que abarcaram, posição que é confirmada quando Vera Brandão descobre, no final da ação, que elas haviam se soltado (ou nunca estiveram amarradas?) e retornado à cidade sem ela.

Nos dois contos, chega-se à conclusão de que as narrativas apresentam protagonistas que nascem para dizer que faltam palavras, como Lídia Jorge afirma na entrevista concedida à Revista Desassossego. Desde o seu romance de estreia, O Dia dos Prodígios, de 1980, a presença feminina ganha um modo específico de escrita, conforme analisa Dalva Calvão ao observar, a partir do que nota a autora acerca da especificidade da escrita sobre mulheres e das diferenças entre homens e mulheres, que:

Lídia Jorge, após admitir sua dificuldade para identificar tais diferenças, acaba por transformar sua resposta em uma lúcida reflexão sobre a experiência feminina, reconhecendo, entre outras coisas, que, tradicionalmente, a mulher "observa, mas não intervém nos actos da construção histórica” e que, portanto, é próprio do discurso feminino "o recuo de quem fala dos elementos circundantes, dos ambientes interiores, os detalhes, os sentimentos subtis, que não são os decisivos, mas os marginais, a escuta de sentimentos não expressos." (VERANI, 2002, p. 114)

A ausência de participação e de intervenção nas ações, assim como a escuta de sentimentos e a interrupção das falas de Lúcia e de Vera Brandão, confirmam a ideia do que é escrever sobre mulheres para Lídia Jorge: um exercício de silêncio e de recuo, expresso, por exemplo, pelo medo de Vera Brandão em relatar o que havia acontecido com ela. Mesmo o medo, ainda que potente, não é expresso pelo grito, como ocorre também com Lúcia na cena final. $\mathrm{O}$ temor cede lugar à vigília, ao monitoramento constante do olhar, como no caso de Lúcia, que vigiava sempre o marido com medo de ser descoberta, ou de Vera, que ouviu cada passo dos homens, cada ação de Margarida, que assistia a tudo com alguma distância e indiferença. Ainda que pareça não existir nenhum sentido em descrever a fraqueza dessas mulheres diante do poder, a escrita de Lídia Jorge denuncia a violação do corpo, a hipocrisia, a violência diária e reforça que não há uma explicação para o que parece ser da "natureza" humana, pois as duas narrativas expõem a falta de sentido para os acontecimentos que resultarão nos finais de Lúcia e de Vera:

(...) a ideia de que para nada havia sentido, que os atos acontecidos uns atrás dos outros, unidos apenas por uma cadeia estúpida engendrada no tempo, e que a estupidez era isso mesmo, cada onda bater a intervalos regulares, fingindo um sentido que não existia. Entre uma onda e outra onda, só outra onda, a formar-se sob a brisa noturna do Levante, mais nada. E isso trazia-lhe a escuridão aos olhos e uma vontade irresistível de se ausentar do mundo. (JORGE, 2014, p. 174) 
Portanto, retornando às considerações iniciais, quando Lídia Jorge afirma que as suas personagens femininas são dotadas da capacidade de olhar tudo à volta e, por essa razão, ao olhar, elas dizem sobre a incompreensão e o medo que sofrem no interior de suas culturas, não é de se espantar que a escrita, que suspende e quebra a expectativa do leitor, esteja aliada a uma perspectiva de construção de uma atmosfera do silêncio, tão caro à história das mulheres no ocidente. Quando reagem - seja por uma postura diferente, como aguardar o marido no lugar de se esconder, seja por meio da ajuda em fazer com que outras mulheres conquistem sua liberdade, como é o caso da missão de Vera -, pagam com os seus corpos, sem nada que justifique completamente as ações, a não ser uma "cadeia estúpida engendrada no tempo" que faz da morte ou da tortura uma redenção silenciosa para a ausência de sentido em não dizer.

A decisão de como operacionalizar a pausa em meio à incessante experiência da linguagem que quer ser constantemente o excesso, dependerá do autor, diria Blanchot (2005). No lugar de produzir o silêncio por meios tipográficos ou por configurações textuais que expressam a lacuna, como parágrafos ausentes ou espaços em branco, Lídia Jorge opta por impor o silêncio por defesa da própria visão da condição feminina. Incapazes de criar, porque são interrompidas de diferentes maneiras, Lúcia morre para conquistar a vida. Vera, por outro lado, emudece para continuar a viver e a salvar outras mulheres. Ambas denunciam, pela falta, a violência que sempre existiu pautada em muitos aspectos, como na distinção entre os corpos. Para enfatizar o silenciamento dos textos, a escritora recorre a uma estratégia inversa: frases curtas, palavras repetidas, como "ruído", "silêncio", "abafar", em "Marido, ou "sentido", "busca”, em "As três mulheres sagradas". No lugar de dar a voz, critica a ausência dela diante do absurdo que é a vida diária e privada das mulheres. Cria uma rede solidária de falas silenciosas.

\section{REFERÊNCIAS BIBLIOGRÁFICAS}

BEAUVOIR, Simone. O Segundo sexo - fatos e mitos. São Paulo: Difusão Européia do Livro, 1980.

BLANCHOT, Maurice. A parte do fogo. Tradução de Ana Maria Scherer. Rio de Janeiro: Rocco, 2005.

BRIDI, Marlise Vaz. Lídia Jorge contista: a face menos visível de uma escritora maior. In: Antologia de Contos. São Paulo: Leya, 2014, p.7-15.

DUNDER, Mauro. A literatura tem um poder lento, mas é um poder seguro. Revista Desassossego n. 8, p. 192-207, dezembro de 2012. Disponível em: http://www.revistas.usp.br/desassossego/.

JORGE, Lídia. Antologia de Contos. São Paulo: Leya, 2014.

PERROT, Michelle. As mulheres ou os silêncios da história. Edusc: Bauru, 2005. 
VERANI, Dalva Calvão. Mulheres de Vilamaninhos: a presença feminina em $O$ dia dos prodígios, de Lídia Jorge. In: DUARTE, Constância Lima; SCARPELLI, Marli Fantini (Orgs.). Gênero e representação nas literaturas de Portugal e África: ensaios. Belo Horizonte: Pós-graduação em Letras: Estudos Literários: UFMG, 2002, p. 114-120. Coleção Mulher e Literatura, v. 3.

Recebido para publicação em 08/03/2017

Aprovado em 26/04/2017

\section{NOTAS}

1 Professora Adjunta de Literatura Portuguesa da Universidade do Estado do Rio de Janeiro (UERJ). Doutora em Literatura Comparada pela Universidade Federal Fluminense (UFF).

2 Entrevista publicada no oitavo número da revista, de dezembro de 2012, intitulada "A literatura tem um poder lento, mas é um poder seguro". No texto, a escritora expõe algumas das suas reflexões acerca da linguagem e de outras questões relevantes para o entendimento da sua escrita. 